\title{
Extrinsic heavy metal atom effect on the solid state room temperature phosphorescence of cyclic triimidazole
}

\author{
Elena Cariati, ${ }^{* a],[b]}$ Alessandra Forni, ${ }^{* b]}$ Elena Lucenti, ${ }^{[b]}$ Daniele Marinotto, ${ }^{[b]}$ Andrea Previtali, ${ }^{[a]}$ \\ Stefania Righetto, ${ }^{[a]}$ Chiara Botta, ${ }^{[c]}$ Victor Bold, ${ }^{[d]}$ Victor Ch. Kravtsov, ${ }^{[d]}$ Marina S. Fonari ${ }^{*[]]}$
}

\begin{abstract}
Four coordination compounds $\left[\mathrm{Zn}_{3}\left(\mathrm{CH}_{3} \mathrm{COO}\right)_{6}\left(\mathrm{H}_{2} \mathrm{O}\right)_{2}\right](\mathrm{TT})_{2}$ $\left[\mathrm{Cd}\left(\mathrm{H}_{2} \mathrm{O}\right)_{6}\right]\left(\mathrm{ClO}_{4}\right)_{2}(\mathrm{TT})_{2},\left[\mathrm{Cd}\left(\mathrm{H}_{2} \mathrm{O}\right)_{6}\right]\left(\mathrm{BF}_{4}\right)_{2}(\mathrm{TT})_{2},\left[\mathrm{Zn}\left(\mathrm{H}_{2} \mathrm{O}\right)_{6}\right]\left(\mathrm{BF}_{4}\right)_{2}(\mathrm{TT})_{2}$ (1-4) accommodating the crystallization induced emissive triimidazo[1,2-a:1',2'-c:1",2"-e][1,3,5]triazine (TT) as a guest in their crystal lattice are isolated and fully photophysically and structurally characterized. Their emission properties are compared with those of afterglow TT and interpreted taking into account the heavy atom effect and crystal packing similarities and differences. In the case of 1 , due to the closeness of the $\mathrm{TT} \mathrm{H}$-aggregates arrangement with that of the phosphor's pure phase, the observed intensification of the phosphorescent emission at the expense of the prompt one is attributed to the extrinsic heavy atom effect of $\mathrm{Zn}$. In 2 and 3, the heavier $\mathrm{Cd}$ atom is responsible for a decrease in the lifetimes of the afterglow emission, despite the presence of tightly overlapped $\mathrm{H}$ dimers in the crystal structure. Finally for $\mathbf{4}$, isostructural with $\mathbf{3}$, the $\mathrm{Zn}$ atom reveals in RTUP lifetime comparable with that of $\mathbf{1}$.
\end{abstract}

\section{Introduction}

Long lived room temperature phosphorescence (RTP) from solid-state materials ${ }^{[1]}$ represents a relatively new issue in the development of AIE functional compounds with applications in data security technologies, temperature monitoring, sensing and bio-imaging. ${ }^{[1 \mathrm{c}, 2]}$ The presence of a solid state afterglow emission can be found in inorganic phosphors but is extremely rare in organometallic compounds due to the small lifetimes of their triplet excitons. Room temperature ultralong phosphorescence (RTUP) has been recognized to occur for some purely organic materials due to the presence in their crystal structure of $\mathrm{H}$ aggregates ${ }^{[3]}$ able to provide stabilization of the excited triplet state by trapping triplet excitons.

In this regard, we have recently reported on the photophysical properties of triimidazo[1,2-a:1',2'-c:1",2"'-e][1,3,5]triazine (TT), which displays crystallization-induced (CIE) and

[a] Prof. E.Cariati, Dr. A. Previtali, Dr. S. Righetto

Dept. Of Chemistry

Università degli Studi di Milano and INSTM RU

Via Golgi 19, 20133 Milano (Italy)

E-mail: elena.cariati@unimi.it

[b] Dr. A. Forni, Dr. E. Lucenti, Dr. D. Marinotto,

ISTM-CNR, INSTM RU

via Golgi 19, 20133 Milano (Italy)

E-mail: a.forni@cnr.istm.it

[c] Dr. C. Botta

ISMAC-CNR, INSTM RU

Via Corti 12, 20133 Milano (Italy)

[d] V. Bold, Dr. V. Ch. Kravtsov, Dr. M. S. Fonari,

Institute of Applied Physics

Academy str., 5 MD2028, Chisinau (Moldova)

E-mail: fonari.xra@phys.asm.md

Supporting information for this article is given via a link at the end of the document. mechanochromic emission, together with RTUP under ambient conditions due to $\mathrm{H}$ aggregation. ${ }^{[4]}$ In addition we investigated the possibility of modulating its phosphorescence by introducing into the molecule (intrinsic effect) a halogen atom $\left(\mathrm{Br}\right.$ or I) ${ }^{[5]}$ or by exploiting specific intermolecular interactions (extrinsic effect) ${ }^{[6]}$ based on halogen bonding with other molecules of the same type (one component) or a different type (two-component e.g. in co-crystals) ${ }^{[5,7]}$

In view of investigating the perturbation induced by a heavy metal atom on ligands' photoluminescence properties, the choice is preferentially directed towards filled-shell $d^{10}$ systems $(\mathrm{Zn}, \mathrm{Cd})^{[8]}$ lacking low lying ligand-field excited states. Moreover, these metals can compete with platinum group compounds in view of their low cost and availability. ${ }^{[9]}$ Based on these considerations, here we compare the luminescence of TT with that of four compounds containing $\mathrm{Zn}$ or $\mathrm{Cd}$. In these compounds the metal is not coordinated by TT but perturbs its photophysics by both altering the supramolecular organization and playing the role of an extrinsic heavy atom.

\section{Results and Discussion}

As previously reported, diluted dichloromethane (DCM) solution of TT displays at $298 \mathrm{~K}$ a weak emission at $390 \mathrm{~nm}(\Phi=2 \%) .{ }^{[4]}$ On the other side, its crystals show a strong, broad, featureless emission centered at $400 \mathrm{~nm}\left(\Phi=30 \%, \lambda_{\mathrm{exc}}=350 \mathrm{~nm}\right)$ which is the result of the superimposition of a prompt $\left(\lambda_{\mathrm{em}}=400 \mathrm{~nm}, \tau\right.$ in the nanosecond regime) and a longer wavelength $\left(\lambda_{\mathrm{em}}=525\right.$ $\mathrm{nm})$ RTUP which lasts for about $3.6 \mathrm{~s}\left(\tau_{\mathrm{av}}=970 \mathrm{~ms}\right)$ and is affected by the degree of crystallinity but is inert to oxygen. Single crystal XRD analysis revealed that the molecules are slightly twisted with respect to an idealized $C_{3 h}$ symmetry and stack in face-to-face antiparallel packed zigzag columns with distances between centroids of the central rings equal to 3.73 and $3.95 \AA$ (Figure 1, left). ${ }^{[10]}$ Such short distances are indicative of strong $\pi-\pi$ interactions in the ground state, associated with a large interchromophoric $\pi$-stacking area and formation of $\mathrm{H}$ aggregates which are responsible for the CIE behavior and are at the basis of the RTUP. ${ }^{[4]}$

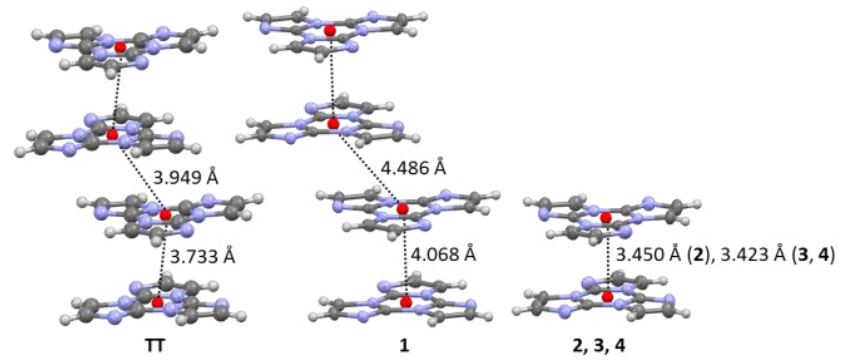

Figure 1. Motives of chromophore's aggregation in TT and in 1-4

For internal use, please do not delete. Submitted_Manuscript 
Aimed at verifying the effect of a metal on TT photoluminescence we have synthetized a series of metal containing derivatives. Among them we have selected and fully spectroscopically analyzed in the solid state cocrystals $\left[\mathrm{Zn}_{3}\left(\mathrm{CH}_{3} \mathrm{COO}\right)_{6}\left(\mathrm{H}_{2} \mathrm{O}\right)_{2}\right](\mathrm{TT})_{2}$ (1) and $\left[\mathrm{M}\left(\mathrm{H}_{2} \mathrm{O}\right)_{6}\right](\mathrm{An})_{2}(\mathrm{TT})_{2}$ where $\mathrm{M}=\mathrm{Cd}, \mathrm{An}=\mathrm{ClO}_{4}^{-}(\mathbf{2}), \mathrm{M}=\mathrm{Cd}, \mathrm{An}=\mathrm{BF}_{4}^{-}(3)$ or $\mathrm{M}=\mathrm{Zn}, \mathrm{An}=\mathrm{BF}_{4}^{-}(4)$. Compound 1 crystallizes in the triclinic $P$-1 space group, and the formula unit comprises the neutral centrosymmetric trinuclear $\mathrm{Zn}$ cluster $\left[\mathrm{Zn}_{3}\left(\mathrm{CH}_{3} \mathrm{COO}\right)_{6}\left(\mathrm{H}_{2} \mathrm{O}\right)_{2}\right]$ and two TT ligands attached by $\mathrm{O}\left(\mathrm{H}_{2} \mathrm{O}\right)-\mathrm{H} \cdots \mathrm{N}=2.754 \AA$ hydrogen bonds (Figure 2 ). In the centrosymmetric coordination entity the central $\mathrm{Zn}$ atom is in $\mathrm{O}_{6}$ octahedral environment (Zn-O distances 2.0497(18)-2.171(2) $\AA$ ), and two terminal $\mathrm{Zn}$ atoms are in the tetrahedral $\mathrm{O}_{4}$ environment with shorter Zn-O distances (1.944(2)-1.990(2) Å). Two acetate anions act in a bidentate bridging mode, and one in monodentate bridging mode. Water molecules complete the tetrahedral surrounding of terminal zinc atoms.

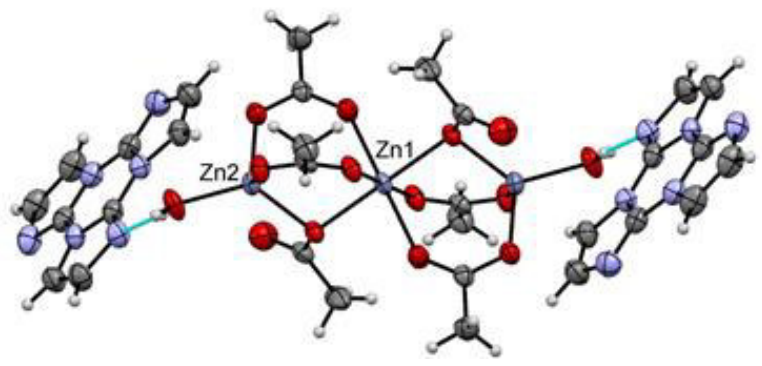

Figure 2. View of formula unit in 1

A survey of $C S D^{[11]}$ reveals very few examples of such type of $\mathrm{Zn}$-carboxylate trinuclear cluster with the alternation of tetrahedral/octahedral metal nodes in the $\mathrm{O}_{4} / \mathrm{O}_{6} / \mathrm{O}_{4}$ coordination environments, all of them represent neutral molecular entities. ${ }^{[12]}$ In the crystal the formula units $\left[\mathrm{Zn}_{3}\left(\mathrm{CH}_{3} \mathrm{COO}\right)_{6}\left(\mathrm{H}_{2} \mathrm{O}\right)_{2}\right](\mathrm{TT})_{2}$ form columns along crystallographic a axis due to $\mathrm{O}\left(\mathrm{H}_{2} \mathrm{O}\right)$ $\mathrm{H} \cdots \mathrm{O}=2.806 \AA$ A hydrogen bonds.

Very interesting, the structure reveals an organization of the TTscaffold reminiscent of that of TT itself (Figure 3). The molecules stack along the crystallographic $b$ axis with distances between centroids of the central rings equal to 4.056 and $4.486 \AA$ (Figure 1 , middle). Such distances are $\sim 8.97 \%$ and $\sim 13.6 \%$ longer than those in TT pure phase. The columns of stacked molecules are united in the layers parallel to $(a b)$ crystallographic plane due to $\mathrm{C}-\mathrm{H} \cdots \mathrm{N}$ hydrogen bond $(\mathrm{C} \cdots \mathrm{N}=3.535 \AA$, Figure $\mathrm{S} 1$, Table S2).

The similarity between the supramolecular chromophore organization in TT and $\mathbf{1}$, is particularly attractive to get information relative to the extrinsic metal atom $(Z n)$ effect.

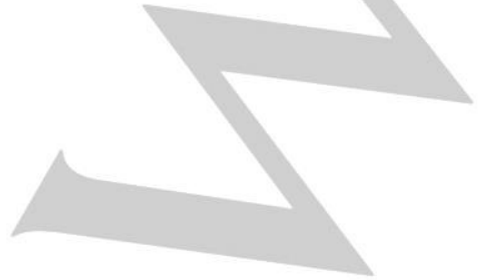

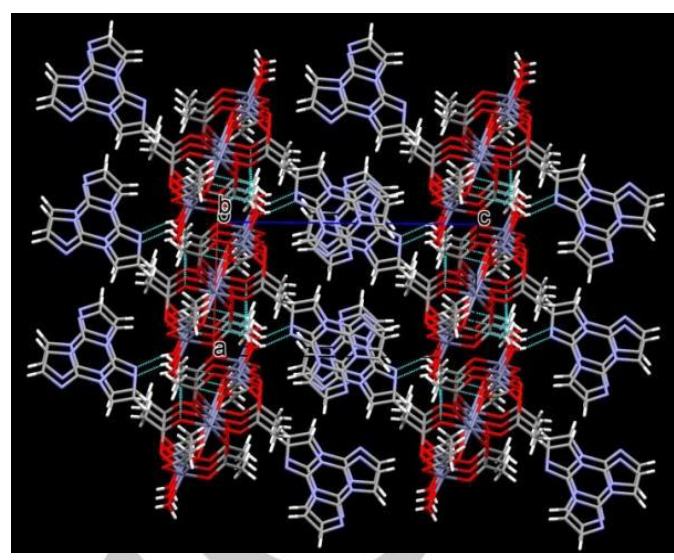

Figure 3. View of crystal packing in 1.

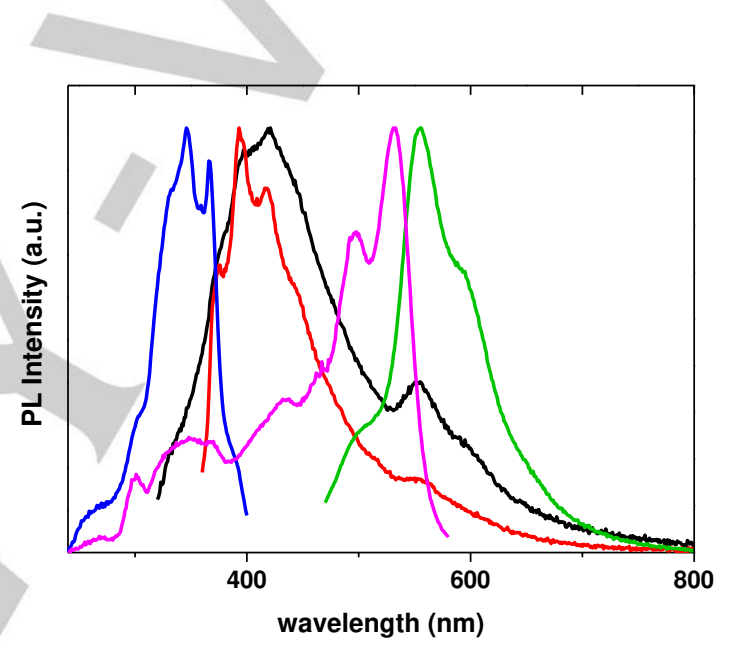

Figure 4. Normalized spectra of crystals of 1 at $298 \mathrm{~K}$ : emission a $\lambda_{\text {exc }}=300 \mathrm{~nm}$ (black line), $\lambda_{\text {exc }}=340 \mathrm{~nm}$ (red line), $\lambda_{\text {exc }}=450 \mathrm{~nm}$ (green line) and excitation at $\lambda_{\mathrm{em}}=416 \mathrm{~nm}$ (blue line), $\lambda_{\mathrm{em}}=600 \mathrm{~nm}$ (pink line).

When excited at $\lambda_{\text {exc }}=340 \mathrm{~nm}$, crystals of 1 display at $298 \mathrm{~K}$ both a fluorescent (at ca $400 \mathrm{~nm}, \tau_{\mathrm{av}}=6.75 \mathrm{~ns}$ see $\mathrm{SI}$ ) and a phosphorescent (at ca $555 \mathrm{~nm}, \tau_{\mathrm{av}}=650 \mathrm{~ms}$ see $\mathrm{SI}$ ) emission (Figures 4 and 9, Table 1) in agreement with the presence of $\mathrm{H}$ aggregates. Intriguingly, the $\mathrm{S}_{0}-\mathrm{T}^{\mathrm{H}}$ transition is clearly visible in the excitation spectrum collected at $\lambda_{\text {em }}=600 \mathrm{~nm}$. The $\mathrm{S}_{0}-\mathrm{T}^{\mathrm{H}}$ mirror image relationship can be clearly observed when monitoring the emission by directly populating $\mathrm{T}^{\mathrm{H}}$ exciting at 416 $\mathrm{nm}$. At $77 \mathrm{~K}$ similar emission and excitation profiles are collected for crystals of 1 with fluorescence $\tau_{\mathrm{av}}$ equal to $8.45 \mathrm{~ns}$ and a phosphorescence $\tau_{\text {av }}$ of $1.3 \mathrm{~s}$ (see SI and Table 1).

The comparison between the photophysics of $\mathbf{1}$ and TT allows to draw the following conclusions regarding the extrinsic role of $\mathrm{Zn}$ atom on the RTUP: i) in $\mathbf{1}$ the increased intensity of the RTUP with respect to the fluorescence is justified by an easier intersystem crossing (ISC) $\mathrm{S}-\mathrm{T}^{\mathrm{H}}$ than in TT, ii) the $\mathrm{S}_{0}-\mathrm{T}^{\mathrm{H}}$ transition becomes detectable in the excitation spectrum, iii) the ISC $\mathrm{T}^{\mathrm{H}}-\mathrm{S}_{0}$ seems not to be greatly affected based on the

For internal use, please do not delete. Submitted_Manuscript 
similarity of 1 and $\mathrm{TT} \mathrm{T}^{\mathrm{H}}$ lifetimes ( $\tau_{\mathrm{av}}$ equal to 650 and $970 \mathrm{~ms}$ respectively, Table 1 ).

Isostructural salt-cocrystals $\mathbf{2}, \mathbf{3}$ and $\mathbf{4}$ crystallize in the centrosymmetric trigonal $R-3$ space group (see Table $\mathrm{S} 1$ in $\mathrm{SI}$ ). The formula units comprise octahedral hexa-aquametal cations $\left[\mathrm{M}\left(\mathrm{H}_{2} \mathrm{O}\right)_{6}\right]^{2+}$ capped by the two symmetry-related tetrahedral anions held in perching tripod positions via three $\mathrm{OH}$ (water) $\cdots \mathrm{Cl}(\mathrm{F})$ hydrogen bonds, and two TT ligands attached to the metal cations via $\mathrm{OH} \cdots \mathrm{N}$ hydrogen bonds (Figure 5 and Table S2 in SI). The Cd-O distances are equal to 2.287(2) and 2.2857(19) $\AA$ in 2, 3, and Zn-O distance is equal to 2.0973(17) $\AA$ in $\mathbf{4}$, respectively in agreement with literature data. ${ }^{[10]}$
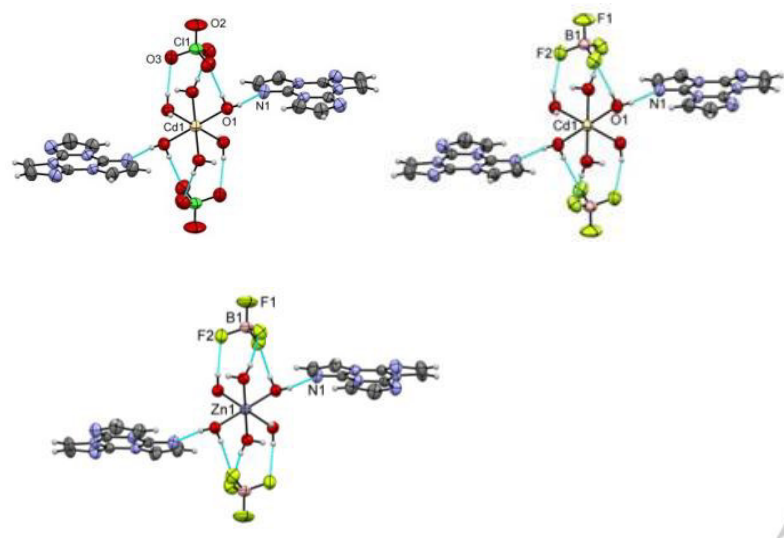

Figure 5. Views of the formula units in compounds 2 (left), 3 (right) and 4 (bottom)

In accordance with the three-fold inversion axis symmetry, each inorganic cation arranges around six TT ligands in two parallel planes (Figure 6) held via $\mathrm{OH} \cdots \mathrm{N}$ hydrogen bonds, while each anion arranges four TT ligands in two parallel planes, three held with the anion via $\mathrm{CH} \cdots \mathrm{O}(\mathrm{F})$ hydrogen bonds (Table S2), and one held with the anion via anion- $\pi$ interactions (the distances between $\mathrm{F} / \mathrm{O}$ and the centroids of the central rings are equal to $2.629 \AA$ for $2,2.669 \AA$ for 3 and $2.644 \AA$ for 4). Thus, each TT chromophore is surrounded by three cations and three anions that exclude the homomeric TT side contacts. TT molecules form stacked dimers by overlapping the central triazine rings with distances between centroids of the central rings equal to $3.450 \AA$ for 2 and $3.423 \AA$ for 3 and 4 , respectively (Figure 1, right and Figure 6). Crystals of 2 show at $298 \mathrm{~K}$ a broad, featureless emission $\left(\lambda_{\text {exc }}=300 \mathrm{~nm}\right)$ which is the result of the superimposition of a prompt component $\left(\lambda_{\text {em }}=421 \mathrm{~nm}, \tau_{\mathrm{av}}=\right.$ $5.20 \mathrm{~ns})$ and a longer wavelength $\left(c a \lambda_{\mathrm{em}}=550 \mathrm{~nm}\right) \operatorname{RTUP}\left(\tau_{\mathrm{av}}=\right.$ $110 \mathrm{~ms}$ ) which can be partially resolved by exciting at $426 \mathrm{~nm}$ and which shows a mirror relationship with its excitation profile (see Figure 7, 9 and Table 1). This phosphorescence seems associated with the presence of $\mathrm{H}$ dimers inside the crystalline structure. Differently from $\mathbf{1}$, in the case of 2 , the relative intensity of the phosphorescent emission with respect of the fluorescent one is not increased. This is unexpected if considering the extrinsic effect of the heavier $\mathrm{Cd}$ atom and suggests a predominant role of the supramolecular organization itself. At $77 \mathrm{~K}$, despite a slight increase of fluorescence lifetime $\left(\tau_{\mathrm{av}}=5.46 \mathrm{~ns}\right.$ see SI), a significant increase of the phosphorescence lifetime is measured $\left(\tau_{\mathrm{av}}=602 \mathrm{~ms}\right.$ see $\mathrm{SI}$ and Table 1).

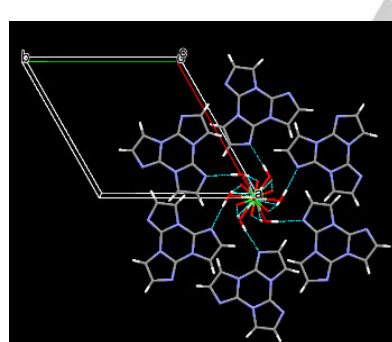

(a)

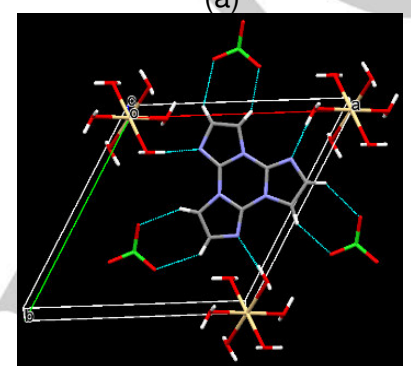

(c)

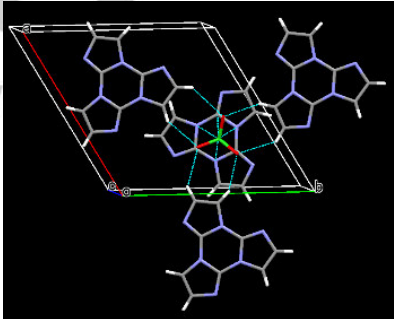

(b)

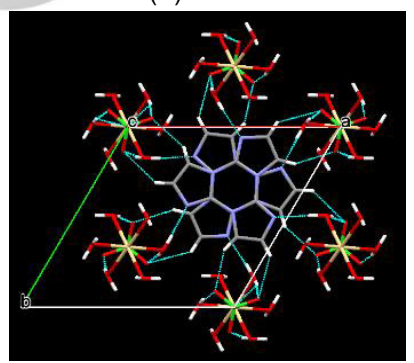

(d)
Figure 6. Fragments of crystal packing in 2 (similar to $\mathbf{3}$ and 4): (a) six TT molecules surround $\left[\mathrm{Cd}\left(\mathrm{H}_{2} \mathrm{O}\right)_{6}\right]^{2+}$ cation; (b) four $\mathrm{TT}$ molecules surround $\mathrm{ClO}_{4}$ anion; (c) the closest environment of $\mathrm{TT}$ molecule via $\mathrm{OH} \cdots \mathrm{N}$ and $\mathrm{CH} \cdots \mathrm{O}$ hydrogen bonds in the ligand's mean plane; (d) top view of the overlapping TT molecules.

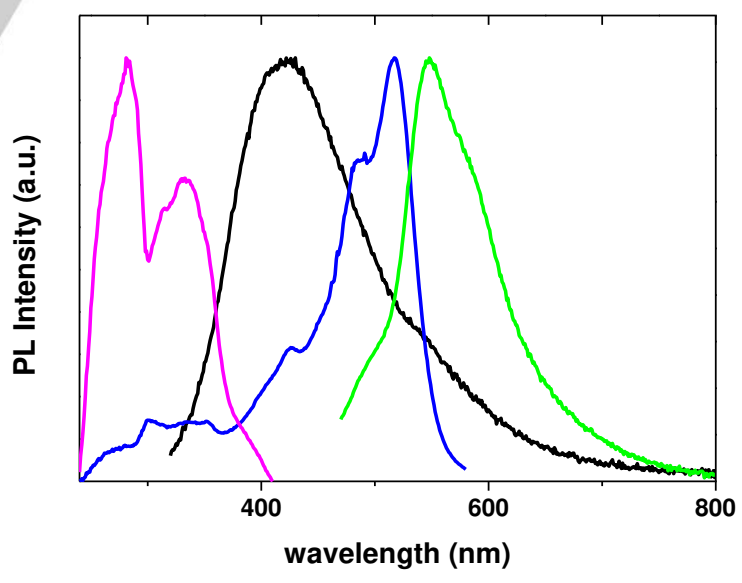

Figure 7. Normalized spectra of crystals of 2 at $298 \mathrm{~K}$ : emission at $\lambda_{\text {exc }}=300 \mathrm{~nm}$ (black line), $\lambda_{\mathrm{exc}}=450 \mathrm{~nm}$ ( $g$ reen line) and excitation at $\lambda_{\mathrm{em}}=426 \mathrm{~nm}$ (pink line), $\lambda_{\text {em }}=600 \mathrm{~nm}$ (blue line) .

Crystals of 3 show at $298 \mathrm{~K}$ a broad emission $\left(\lambda_{\text {exc }}=280 \mathrm{~nm}\right)$ which is the result of the superimposition of a prompt component $\left(\lambda_{\mathrm{em}}=383 \mathrm{~nm}, \tau_{\mathrm{av}}=17.16 \mathrm{~ns}\right.$, see Figure 8$)$ and a longer wavelength RTUP which can be partially resolved when exciting

For internal use, please do not delete. Submitted_Manuscript 
at higher energy $\left(\lambda_{\mathrm{exc}}=340 \mathrm{~nm}, \lambda_{\mathrm{em}}=441,469 \mathrm{~nm}, \tau_{\mathrm{av}}=125 \mathrm{~ms}\right.$, see Figures 8, 9 and Table 1). At $77 \mathrm{~K}$, fluorescent lifetime shows only a minor increase ( $\left.\tau_{\mathrm{av}}=18.71 \mathrm{~ns}\right)$ while a significant increase of the phosphorescence lifetime $\left(\tau_{\mathrm{av}}=753 \mathrm{~ms}\right.$, see SI and Table 1) is observed.

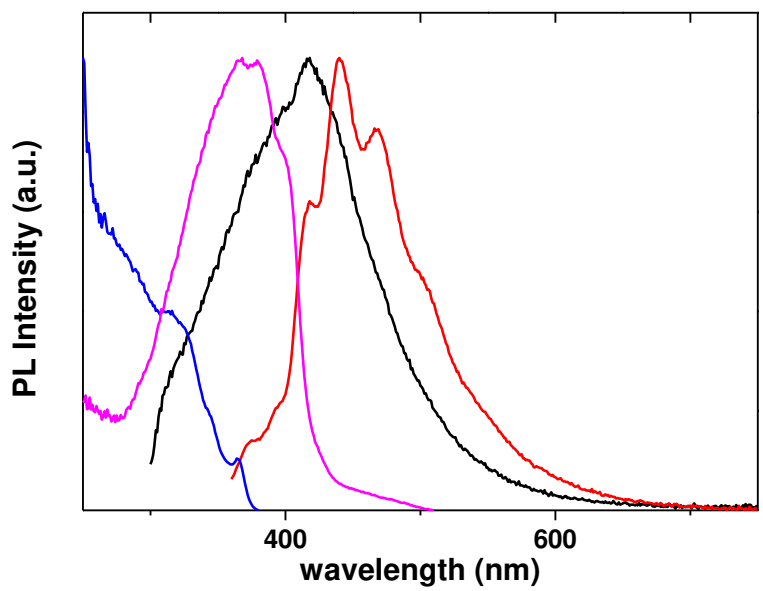

Figure 8. Normalized spectra of crystals of 3 at $298 \mathrm{~K}$ : emission at $\lambda_{\text {exc }}=280 \mathrm{~nm}$ (black line), $\lambda_{\text {exc }}=340 \mathrm{~nm}$ (red line) and excitation at $\lambda_{\text {em }}=390 \mathrm{~nm}$ (blue line), $\lambda_{\mathrm{em}}=530 \mathrm{~nm}$ (pink line)

Crystals of 4 show at $298 \mathrm{~K}$ a broad emission $\left(\lambda_{\text {exc }}=300 \mathrm{~nm}\right)$ which is the result of the superimposition of a prompt component $\left(\lambda_{\mathrm{em}} \cong 370 \mathrm{~nm}, \tau_{\mathrm{av}}=3.52 \mathrm{~ns}\right.$, see SI) and a longer wavelength RTUP which can be partially resolved when exciting at higher energy $\left(\lambda_{\text {exc }}=340 \mathrm{~nm}, \lambda_{\text {em }}=394,422 \mathrm{~nm}, \tau_{\mathrm{av}}=542 \mathrm{~ms}\right.$, see SI and Table 1). At $77 \mathrm{~K}$, fluorescent lifetime shows only a very minor increase ( $\tau_{\mathrm{av}}=5.66 \mathrm{~ns}$ ) while, as already observed for 2 and 3 , a significant increase of the phosphorescence lifetime ( $\tau_{\mathrm{av}}$ $=1.29 \mathrm{~s}$, see SI and Table 1) is observed, suggesting that thermal vibrations affect the long lived emissions of the three compounds. In agreement with the similarity of the crystal structures of 2-4, the features of the RTUP of the three compounds are almost the same. It is however to be noted the significant blue shift of the emission of $\mathbf{3}$ and $\mathbf{4}$ with respect to 2 . To rationalize the observed blue shift of the emission going from 2 to 3 and 4, DFT and TDDFT calculations have been performed on the anion- $\pi$ interacting units $\mathbf{T T} \cdot \mathbf{C l O}_{4}{ }^{-}$and $\mathbf{T T} \cdot \mathbf{B F}_{4}{ }^{-}$, which are deemed mainly responsible for the emissive properties of 2 and 3-4, respectively. The optimized structures, corresponding to quite large interaction energies $(-6.60$ and $-9.40 \mathrm{kcal} / \mathrm{mol}$ for $\mathrm{TT} \cdot \mathrm{ClO}_{4}^{-}$and $\mathrm{TT}^{-} \mathrm{BF}_{4}^{-}$, respectively), preserve their $C_{3}$ symmetry observed in solid state, though the optimized distances between $\mathrm{O} / \mathrm{F}$ and the centroid of the central ring of TT (2.535 and $2.493 \AA$ for $\mathbf{T T} \cdot \mathrm{ClO}_{4}^{-}$and $\mathbf{T T} \cdot \mathrm{BF}_{4}^{-}$, respectively) are slightly shorter than the experimental ones. The computed $\mathrm{S}_{0}-\mathrm{S}_{1}$ excitation energies (see Figure S30), are essentially the same for the two dimers, but analysis of the molecular orbitals mainly involved in this transition reveals significant differences. While the HOMOs of $\mathbf{T T} \cdot \mathbf{B F}_{4}{ }^{-}$are essentially localized on $\mathbf{T T}$, those of $\mathbf{T T} \cdot \mathbf{C l O}_{4}{ }^{-}$are delocalized on both interacting units, suggesting in the latter case charge transfer character for the $\mathrm{S}_{0}-\mathrm{S}_{1}$ transition. The CT character of the relaxed emissive $S_{1}$ level of 2 is probably responsible for the observed red shift with respect to $\mathbf{3}$ and $\mathbf{4}$.

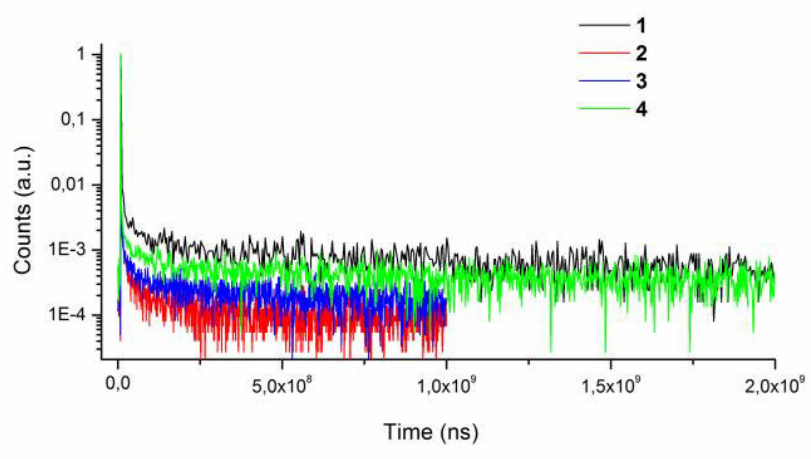

Figure 9. Phosphorescence decays of crystals of 1-4 at $298 \mathrm{~K}$.

\section{Conclusions}

Starting from cyclic triimidazole, which shows CIE behaviour and long afterglow emission at room temperature, we have here investigated the modulation of the emissive properties in its cocrystals with different complexes of $\mathrm{Zn}$ and $\mathrm{Cd}$. Compound 1, in which TT organizes in $\mathrm{H}$ aggregates very similar to those of TT pure phase, allows to clearly identify the extrinsic heavy metal $(Z n)$ effect on the chromophore's photophysics. In particular, the increased SOC manifests in the intensification of the RTUP with respect to the fluorescence due to the easier S$\mathrm{T}^{\mathrm{H}}$ ISC and in the appearance of the $\mathrm{S}_{0}-\mathrm{T}^{\mathrm{H}}$ transition in the excitation spectrum. In $\mathbf{2}$ and $\mathbf{3}$ the heavier metal atom (Cd) acts not only through a more effective SOC resulting in faster radiative and non-radiative rates, but also modifying the TT supramolecular organization. In these structures in fact, TT molecules form stacked dimers by overlapping the central triazine rings. The overall effect is the presence of RTUP emission with significantly shorter lifetimes. The different heavy atom effect exerted by $\mathrm{Cd}$ vs. $\mathrm{Zn}$ is nicely illustrated by the isostructural complexes 3 and 4 , respectively, the former characterized by reduced RTUP lifetimes. Finally, the counterion in $\mathbf{2}$ is responsible for its red shifted (with respect to $\mathbf{3}$ and $\mathbf{4}$ ) fluorescence which possesses CT character. These results provide further contributions in the knowledge of RTUP from extrinsically perturbed organic materials in the solid state. 
Table 1. Photoluminescence data at 298 and 77K. Values for TT are taken from reference [4].

\begin{tabular}{|c|c|c|c|c|c|c|c|}
\hline \multirow[b]{2}{*}{ Sample } & \multirow[b]{2}{*}{$\Phi(\%)$} & & $298 \mathrm{~K}$ & & & $77 \mathrm{~K}$ & + \\
\hline & & $\begin{array}{l}\lambda_{\mathrm{em}} \\
(\mathrm{nm})\end{array}$ & $\tau$ & Origin & $\begin{array}{l}\lambda_{\mathrm{em}} \\
(\mathrm{nm})\end{array}$ & $\tau$ & Origin \\
\hline \multirow[b]{2}{*}{$\underset{\text { (cryst) }}{\mathrm{TT}}$} & \multirow{2}{*}{30} & 400 & $\begin{array}{c}0.17 \mathrm{~ns}(0.81), \\
\left(0.04 \mathrm{~ns}^{\mathrm{a}}(0.16), 15.29 \mathrm{~ns}\right.\end{array}$ & $\mathrm{S}_{1}-\mathrm{S}_{0}$ & 403 & $1.71 \mathrm{~ns}(0.70), 8.49 \mathrm{~ns}(0.30)^{\mathrm{c}}$ & $\mathrm{S}_{1}-\mathrm{S}_{0}$ \\
\hline & & 525 & $\begin{array}{c}10 \mathrm{~ms}(0.10), 52 \mathrm{~ms}(0.25) \\
990 \mathrm{~ms}(0.65)^{\mathrm{b}}\end{array}$ & $\mathrm{T}_{1}^{\mathrm{H}}-\mathrm{S}_{0}$ & 510 & $510 \mathrm{~ms}(0.14), 1.12 \mathrm{~s}(0.86)^{d}$ & $\mathrm{~T}_{1}^{\mathrm{H}}-\mathrm{S}_{0}$ \\
\hline \multirow[b]{2}{*}{$\begin{array}{c}1 \\
\text { (cryst) }\end{array}$} & \multirow[b]{2}{*}{7} & $375,395,418$ & $2.47 \mathrm{~ns}(0.55), 8.29 \mathrm{~ns}(0.45)^{\mathrm{e}}$ & $\mathrm{S}_{1}-\mathrm{S}_{0}$ & 416 & $2.46 \mathrm{~ns}(0.61), 10.62 \mathrm{~ns}(0.39)^{\mathrm{e}}$ & $\mathrm{S}_{1}-\mathrm{S}_{0}$ \\
\hline & & 555 & $17.42 \mathrm{~ms}(0.16), 654.06 \mathrm{~ms}(0.84)^{\mathrm{f}}$ & $\mathrm{T}_{1}^{\mathrm{H}}-\mathrm{S}_{0}$ & 554 & $\begin{array}{c}83.36 \mathrm{~ms}(0.12) \\
464.07 \mathrm{~ms}(0.29) \\
1.450 \mathrm{~s}(0.59)^{\mathrm{g}}\end{array}$ & $\mathrm{T}_{1}^{\mathrm{H}}-\mathrm{S}_{0}$ \\
\hline \multirow{2}{*}{$\begin{array}{c}2 \\
\text { (cryst) }\end{array}$} & \multirow{2}{*}{10} & 421 & $\begin{array}{c}0.32 \mathrm{~ns}(0.20), 1.93 \mathrm{~ns}(0.55) \\
7.24 \mathrm{~ns}(0.25)^{\mathrm{c}}\end{array}$ & $\mathrm{S}_{1}-\mathrm{S}_{0}$ & 440 & $\begin{array}{c}1.09 \mathrm{~ns}(0.43), 3.27 \mathrm{~ns}(0.44) \\
9.68 \mathrm{~ns}(0.13)^{\mathrm{i}}\end{array}$ & $\mathrm{S}_{1}-\mathrm{S}_{0}$ \\
\hline & & 549 & $11.09 \mathrm{~ms}(0.30), 114.07 \mathrm{~ms}(0.70)^{\mathrm{h}}$ & $\mathrm{T}_{1}^{\mathrm{H}}-\mathrm{S}_{0}$ & ca 550 & $\begin{array}{c}96.65 \mathrm{~ms}(0.31) \\
647.47 \mathrm{~ms}(0.69)^{\mathrm{h}} \\
\end{array}$ & $\mathrm{T}_{1}^{\mathrm{H}}-\mathrm{S}_{0}$ \\
\hline \multirow{2}{*}{$\begin{array}{c}3 \\
\text { (cryst) }\end{array}$} & \multirow{2}{*}{16} & 383 & $\begin{array}{c}0.67 \mathrm{~ns}(0.26), 3.42 \mathrm{~ns}(0.36) \\
19.79 \mathrm{~ns}(0.38)^{\mathrm{j}}\end{array}$ & $\mathrm{S}_{1}-\mathrm{S}_{0}$ & 390 & $4.85 \mathrm{~ns}(0.67), 24.23 \mathrm{~ns}(0.33)^{\mathrm{k}}$ & $\mathrm{S}_{1}-\mathrm{S}_{0}$ \\
\hline & & 441,469 & $16.98 \mathrm{~ms}(0.19), 296.46 \mathrm{~ms}(0.81)^{\mathrm{h}}$ & $\mathrm{T}_{1}^{\mathrm{H}}-\mathrm{S}_{0}$ & 441,471 & $\begin{array}{l}127.62 \mathrm{~ms}(0.34), \\
804.27 \mathrm{~ms}(0.66)^{\mathrm{h}}\end{array}$ & $\mathrm{T}_{1}^{\mathrm{H}}-\mathrm{S}_{0}$ \\
\hline \multirow{2}{*}{$\begin{array}{c}\mathbf{4} \\
\text { (cryst) }\end{array}$} & \multirow[t]{2}{*}{9} & 370 & $1.86 \mathrm{~ns}(0.82), 5.91 \mathrm{~ns}(0.18)^{\prime}$ & $\mathrm{S}_{1}-\mathrm{S}_{0}$ & 371 & $\begin{array}{l}1.06 \mathrm{~ns}(0.23), \\
3.11 \mathrm{~ns}(0.56), \\
8.71 \mathrm{~ns}(0.21)^{\mathrm{m}} \\
\end{array}$ & $\mathrm{S}_{1}-\mathrm{S}_{0}$ \\
\hline & & 394,422 & $35.58 \mathrm{~ms}(0.18), 548.65 \mathrm{~ms}(0.82)^{\mathrm{h}}$ & $\mathrm{T}_{1}^{\mathrm{H}}-\mathrm{S}_{0}$ & 397,422 & $162.8 \mathrm{~ms}(0.23), 1.33 \mathrm{~s}(0.77)^{\mathrm{n}}$ & $\mathrm{T}_{1}^{\mathrm{H}}-\mathrm{S}_{0}$ \\
\hline
\end{tabular}

[a] $\lambda_{\mathrm{em}}=400 \mathrm{~nm} \lambda_{\mathrm{exc}}=360 \mathrm{~nm} ;[\mathrm{b}] \lambda_{\mathrm{em}}=570 \mathrm{~nm} \lambda_{\mathrm{exc}}=360 \mathrm{~nm} ;[\mathrm{c}] \lambda_{\mathrm{em}}=420 \mathrm{~nm} \lambda_{\mathrm{exc}}=375 \mathrm{~nm} ;[\mathrm{d}] \lambda_{\mathrm{em}}=540 \mathrm{~nm} \lambda_{\mathrm{exc}}=350 \mathrm{~nm} ;[\mathrm{e}] \lambda_{\mathrm{em}}=416 \mathrm{~nm} \lambda_{\mathrm{exc}}=$ $374 \mathrm{~nm} ;[\mathrm{f}] \lambda_{\mathrm{em}}=560 \mathrm{~nm} \lambda_{\text {exc }}=370 \mathrm{~nm} ;[\mathrm{g}] \lambda_{\mathrm{em}}=555 \mathrm{~nm} \lambda_{\mathrm{exc}}=350 \mathrm{~nm} ;[\mathrm{h}] \lambda_{\mathrm{em}}=550 \mathrm{~nm} \lambda_{\text {exc }}=340 \mathrm{~nm}$; [i] $\lambda_{\mathrm{em}}=409 \mathrm{~nm} \lambda_{\text {exc }}=375$; [j] $\lambda_{\text {em }}=348 \mathrm{~nm} \lambda_{\text {exc }}$ $=300 ;[\mathrm{k}] \lambda_{\mathrm{em}}=395 \mathrm{~nm} \lambda_{\mathrm{exc}}=300 ;[1] \lambda_{\mathrm{em}}=380 \mathrm{~nm} \lambda_{\mathrm{exc}}=300 ;[\mathrm{m}] \lambda_{\mathrm{em}}=370 \mathrm{~nm} \lambda_{\mathrm{exc}}=300 ;[\mathrm{n}] \lambda_{\mathrm{em}}=410 \mathrm{~nm} \lambda_{\mathrm{exc}}=340$.

Teflon-lined reactor, heated $\left(0.41(6)^{\circ} \mathrm{C} / \mathrm{min}\right.$ rate) in an oven at $80^{\circ} \mathrm{C}$ for $24 \mathrm{~h}$ and slowly $\left(0.023^{\circ} \mathrm{C} / \mathrm{min}\right.$ rate) cooled to $30^{\circ} \mathrm{C}$. Then the reaction mixtures were filtered off and left for crystallization at room temperature. The identity of compounds was confirmed by IR, X-ray single crystal and

\section{Experimental Section}

General Information. All reagents were purchased from chemical suppliers and used without further purification unless otherwise stated. Triimidazo[1,2-a:1',2'-c:1",2"-e][1,3,5]triazine (TT) was prepared according to literature procedures. ${ }^{[10]}$ Steady state emission and excitation spectra and photoluminescence lifetimes were obtained using a FLS 980 (Edinburg Instrument Ltd) and a Nanolog (Horiba Scientific) spectrofluorimeter. The steady state measurements were recorded by a $450 \mathrm{~W}$ Xenon arc lamp. Photoluminescence lifetime measurements were performed using: Edinburgh Picosecond Pulsed Diode Laser EPL-375, EPLED-300, (Edinburg Instrument Ltd) and microsecond flash Xe-lamp $(60 \mathrm{~W}, 0.1 \div 100 \mathrm{~Hz}$ ) with data acquisition devices time correlated singlephoton counting (TCSPC) and multi-channel scaling (MCS) methods, respectively. Average lifetimes are obtained as $\tau_{\mathrm{av}}=\left(\sum A_{i} \tau_{i}^{2}\right) /\left(\sum A_{i} \tau_{i}\right)$ from bi-exponential or three-exponential fits. Low temperature measurements are performed by immersion of the sample in a LN2 quartz dewar or with a variable temperature liquid nitrogen cryostat Oxford DN1704. IR spectra were obtained in $\mathrm{KBr}$ pellets on a FT IR Spectrum-100 Perkin Elmer spectrometer in the range of $400-4000 \mathrm{~cm}^{-1}$. X-ray powder diffraction data were collected with a DRON-UM X-ray powder diffractometer equipped with a $\mathrm{Fe}-\mathrm{Ka}$ radiation source. Data were collected over an angle range of $5-50^{\circ}$ at a scanning speed of $5^{\circ}$ per minute.

General synthetic procedure for 1-4. Solvothermal syntheses for 1-4 were performed in the same synthetic conditions using a sealed $12-\mathrm{mL}$ powder diffraction data (See SI).

Compound 1. In a Teflon beaker, in $\mathrm{CH}_{3} \mathrm{CN}(8 \mathrm{~mL})$ was added $\mathrm{Zn}\left(\mathrm{CH}_{3} \mathrm{COO}\right)_{2}(18.1 \mathrm{mg}, 0.098 \mathrm{mmol})$ and TT $(20.2 \mathrm{mg}, 0.101 \mathrm{mmol})$. Transparent colourless crystals were precipitated in a week. Yield: 26.7 $\mathrm{mg} \quad(85.0 \%)$ \%). IR $(\mathrm{KBr}) / \mathrm{cm}^{-1}: \quad 3388.9(\mathrm{w}), \quad 3111.0(\mathrm{~m}), \quad 2986.5(\mathrm{w})$, $1602.5($ v.s.), $1587.6($ sh. v.s.), $1446.9(\mathrm{sh}), \quad 1424.2(\mathrm{~s}), \quad 1323.5(\mathrm{~s})$, 1307.0(sh., s.), 1238.2 (m), 1124.7(s), 1049(m), 1027.8(sh), 928.4(w), 917.6(w), 901.3(w), 884.1(w), 758.2(sh), 734.1(m), 679.1(s).

Compound 2. In a Teflon beaker, in $\mathrm{CH}_{3} \mathrm{CN}$ (8 mL) was added $\mathrm{Cd}\left(\mathrm{ClO}_{4}\right)_{2} \cdot \mathrm{xH}_{2} \mathrm{O}(37.6 \mathrm{mg}, 0.120 \mathrm{mmol})$, and $\mathrm{TT}(26.7 \mathrm{mg}, 0.134 \mathrm{mmol})$ Then mixture was heated under solvothermal conditions. Transparent colourless crystals were precipitated in a week. Yield: $53.8 \mathrm{mg}(55.0 \%)$. IR $(\mathrm{KBr}) / \mathrm{cm}^{-1}$ : 3467.1(s), 3160.8(m) 3137.4(sh), 2988.2(m), 2972.0(br., s.), 2923.1 (br., m.), 1611.3 (v.s.), 1511(w), 1460.8(s), 1417.6(sh), 1324.8(s), 1244.0(m), 1127.7(s), 111.7(sh, s), 1067.0(v.s.), 1054.3(sh., v.s.), $932.9(w), 914.9(w), 866.1(w), 738.0(s), 688.4(s)$.

Compound 3. In a Teflon beaker, in $\mathrm{CH}_{3} \mathrm{CN}$ (8 mL) was added $\mathrm{Cd}\left(\mathrm{BF}_{4}\right)_{2} \cdot 6 \mathrm{H}_{2} \mathrm{O}(35.9 \mathrm{mg}, 0.091 \mathrm{mmol})$ and $\mathrm{TT}(21.5 \mathrm{mg}, 0.108 \mathrm{mmol})$. Then mixture was heated under solvothermal conditions. Transparent colourless crystals were precipitated in a week. Yield $35.97 \mathrm{mg}(50.0 \%)$. IR $(\mathrm{KBr}) / \mathrm{cm}^{-1}: \quad 3515.4(\mathrm{~s}), \quad 3164.0(\mathrm{~m}), \quad 3140.3(\mathrm{sh}, \mathrm{w}), \quad 2954.3(\mathrm{sh})$, 2923.3(s), 2855.6(sh), 2162.3(v.w), 1732.9 (w), 1678.6(w), 1611.6(v.s.), $1512.9(w), \quad 1484.4(w), \quad 1463.0(s), \quad 1380.1(w), \quad 1325.5(s), \quad 1244.9(w)$, 
1159.0(m) $\quad 1111.6(\mathrm{~s}), \quad 1069.9(\mathrm{~s}) \quad 1017.4(\mathrm{v} . \mathrm{s}),. \quad 915.6(\mathrm{w}), \quad 868.6(\mathrm{~m})$ $768.4(\mathrm{~m}), 740.8(\mathrm{~s}), 690.6(\mathrm{~s})$.

Compound 4. In a Teflon beaker, in $\mathrm{CH}_{3} \mathrm{CN}$ (8 mL) was added $\mathrm{Zn}\left(\mathrm{BF}_{4}\right)_{2} \cdot \mathrm{H}_{2} \mathrm{O}(23.39 \mathrm{mg}, 0.091 \mathrm{mmol})$ and TT $(21.5 \mathrm{mg}, 0.108 \mathrm{mmol})$. Then mixture was heated under solvothermal conditions. Transparent colourless crystals were precipitated in a week. Yield $33.8 \mathrm{mg}(50.0 \%)$. IR $(\mathrm{KBr}) / \mathrm{cm}^{-1}: \quad 3566.7(\mathrm{sh}), \quad 3519.9 .0(\mathrm{~m}), \quad 3474.6(\mathrm{sh}), 3166.6(\mathrm{sh}, \mathrm{m})$ 3143.5, 2953.2(sh), 2923.2(s), 2854.1(sh), 1660.8(m), 1614.2(v.s.), 1518.8(w), 1461.0(s), 1430.7(sh), 1367(sh), 1325.7(m), 1244.1(w), $1160.7(\mathrm{w}) 1128.7$ (sh,m) 1110.6(s), 1064.0(s) 1019.6(v.s.), 914.7(w) $865.1(\mathrm{~m}), 769.0(\mathrm{w}), 739.1(\mathrm{~s}), 690.8$ (v.s.)

Crystallographic Studies. Diffraction measurements for 1-4 were carried out on an Xcalibur E diffractometer equipped with a CCD area detector and a graphite monochromator utilizing MoKa radiation at a room temperature. Final unit cell dimensions were obtained and refined on an entire data set. All calculations to solve the structures and to refine the models proposed were carried out with the programs SHELXS97 and SHELXL2014. ${ }^{[13]}$ Hydrogen atoms attached to carbon atoms were positioned geometrically and treated as riding atoms using SHELXL default parameters with $\mathrm{U}_{\text {iso }}(\mathrm{H})=1.2 \mathrm{U}_{\mathrm{eq}}(\mathrm{C}) / 1.5 \mathrm{U}_{\mathrm{eq}}(\mathrm{C})$. The $\mathrm{H}$-atoms in water molecules were located at difference Fourier maps and refined using the geometric restraints $[\mathrm{d}(\mathrm{O}-\mathrm{H})=0.86 \AA \AA \mathrm{A}(\mathrm{H} \cdots \mathrm{H})=1.46 \AA$ ] $]$. The $\mathrm{X}-$ ray data and the details of the refinement for $\mathbf{1 - 4}$ are summarized in Table S1, H-bonded distances are given in Table S2. The Figures were produced using Mercury. ${ }^{[14]}$ Crystallographic data for structures reported herein were deposited with the Cambridge Crystallographic Data Centre and allocated the deposition numbers CCDC 1875063-1875065, and CCDC 1886104. These data can be obtained free of charge from the Cambridge Crystallographic Data Centre via www.ccdc.cam.ac.uk/data request/cif

Computational Studies. DFT and TDDFT calculations on TT. $\mathrm{ClO}_{4}{ }^{-}$and $\mathrm{TT} \cdot \mathrm{BF}_{4}{ }^{-}$dimers were performed with Gaussian 16 program (Revision A.03 $)^{[15]}$ using the $6-311++G(d, p)$ basis set and the $\omega B 97 X$ functional, ${ }^{[16]}$ in agreement with our previous calculations on $T T .{ }^{[4]}$ Their geometries have been freely optimized starting from those of the respective fragments extracted from the X-ray structures of $\mathbf{2}$ and $\mathbf{3}$. The interaction energies were computed as the difference between the energies of the dimer and those of the isolated monomers.

\section{Acknowledgements}

Authors are grateful to the ASM (18.80013.16.03.03/It) - CNR Bilateral Project 2018-2019 for granting. The use of instrumentation purchased through the Regione LombardiaFondazione Cariplo joint SmartMatLab Project is gratefully acknowledged.

Keywords: room temperature ultralong phosphorescence • extrinsic heavy atom effect $\bullet \mathrm{H}$ aggregates $\bullet$ single crystal XRD -time resolved photoluminescence

[1] a) M. Baroncini, G. Bergamini, P. Ceroni, Chem. Commun. 2017, 53, 2081-2093; b) A. Forni, E. Lucenti, C. Botta, E. Cariati, J. Mater. Chem. C 2018, 6, 4603-4626; c) S. Hirata, Adv. Opt. Mater. 2017, 5, 1700116 d) S. Xu, R. Chen, C. Zheng, W. Huang, Adv. Mater. 2016, 28, 99209940.
[2] a) H. Bhatia, I. Bhattacharjee, D. Ray, J. Phys. Chem. Lett. 2018, 9 3808-3813; b) X. Ma, C. Xu, J. Wang, H. Tian, Angew. Chem., Int. Ed. 2018, 57, 10854-10858; c) L. Xu, G. Li, T. Xu, W. Zhang, S. Zhang, S. Yin, Z. An, G. He, Chem. Commun. 2018, 54, 9226-9229; d) L. Gu, H. Shi, C. Miao, Q. Wu, Z. Cheng, S. Cai, M. Gu, C. Ma, W. Yao, Y. Gao, Z. An, W. Huang, J. Mater. Chem. C 2018, 6, 226-233; e) Q. Wu, H. Ma, K. Ling, N. Gan, Z. Cheng, L. Gu, S. Cai, Z. An, H. Shi, W. Huang, ACS Appl. Mater. Interfaces 2018, 10, 33730-33736; f) Z. C. Cheng, H. F. Shi, H. L. Ma, L. F. Bian, Q. Wu, L. Gu, S. Z. Cai, X. Wang, W. W. Xiong, Z. F. An, W. Huang, Angew. Chem., Int. Ed. 2018, 57, 678-682 g) S. M. A. Fateminia, Z. Mao, S. Xu, Z. Yang, Z. Chi, B. Liu, Angew. Chem., Int. Ed. 2017, 56, 12160-12164; h) Z. Chai, C. Wang, J. Wang, F. Liu, Y. Xie, Y. Z. Zhang, J. R. Li, Q. Li, Z. Li, Chem. Sci. 2017, 8, 8336-8344.

[3] a) Z. An, C. Zheng, Y. Tao, R. Chen, H. Shi, T. Chen, Z. Wang, H. Li, R. Deng, X. Liu, W. Huang, Nat. Mater. 2015, 14, 685-690; b) S. Z. Cai, H. F. Shi, J. W. Li, L. Gu, Y. Ni, Z. C. Cheng, S. Wang, W. W. Xiong, L. Li, Z. F. An, W. Huang, Adv. Mater. 2017, 29, 1701244; c) S. Z. Cai, H. F. Shi, D. Tian, H. L. Ma, Z. C. Cheng, Q. Wu, M. X. Gu, L. Huang, Z. F. An, Q. Peng, W. Huang, Adv. Funct. Mater. 2018, 28, 1705045; d) Z. C. Cheng, H. F. Shi, H. L. Ma, L. F. Bian, Q. Wu, L. Gu, S. Z. Cai, X. Wang, W. W. Xiong, Z. F. An, W. Huang, Angew. Chem., Int. Ed. 2018, 57, 678-682; e) S. Pan, Z. Chen, X. Zheng, D. Wu, G. Chen, J. Xu, H. Feng, Z. Qian, J. Phys. Chem. Lett. 2018, 9, 3939-3945.

[4] E. Lucenti, A. Forni, C. Botta, L. Carlucci, C. Giannini, D. Marinotto, A Previtali, S. Righetto, E. Cariati, J. Phys. Chem. Lett. 2017, 8, 1894 1898

[5] a) E. Lucenti, A. Forni, C. Botta, L. Carlucci, A. Colombo, C. Giannini, D. Marinotto, A. Previtali, S. Righetto, E. Cariati, ChemPhotoChem 2018 2, 801-805; b) E. Lucenti, A. Forni, C. Botta, L. Carlucci, C. Giannini, D. Marinotto, A. Pavanello, A. Previtali, S. Righetto, E. Cariati, Angew. Chem. Int. Ed. 2017, 56, 16302-16307; c) E. Lucenti, A. Forni, C. Botta, C. Giannini, D. Marinotto, A. Previtali, S. Righetto, E. Cariati, submitted for publication.

[6] a) M. Kasha, J. Chem. Phys. 1952, 20, 71-74; b) S. P. McGlynn, R Sunseri, N. Christodouleas, J. Chem. Phys. 1962, 37, 1818-1824; c) X Sun, B. Zhang, X. Li, C. O. Trindle, G. Zhang, J. Phys. Chem. A 2016 120, 5791-5797; d) J. Wang, X. Gu, M. Huili, Q. Peng, X. Huang, X. Zheng, S. H. P. Sung, G. Shan, J. W. Y. Lam, Z. Shuai, B. Z. Tang, Nat. Commun. 2018, 9, 2963.

[7] a) A. Khan, M. Wang, R. Usman, H. Sun, M. Du, C. Xu, Cryst. Growth Des. 2017, 17, 1251-1257; b) W. Zhu, R. Zheng, Y. Zhen, Z. Yu, H. Dong, H. Fu, Q. Shi, W. Hu, J. Am. Chem. Soc. 2015, 137, 1103811046; c) D. Yan, A. Delori, G. O. Lloyd, T. Friščić, G. M. Day, W. Jones, J. Lu, M. Wei, D. G. Evans, X. Duan, Angew. Chem. Int. Ed. 2011, 50, 12483-12486.

[8] a) D. Chisca, L. Croitor, O. Petuhov, O. V. Kulikova, G. F. Volodina, E. B. Coropceanu, A. E. Masunov, M. S. Fonari, CrystEngComm 2018, 20, 432-447; b) T. Qu, Q. Wei, C. Ordonez, J. Lindline, M. Petronis, M. S. Fonari, T. Timofeeva, Crystals 2018, 8, 162 (19 pages); c) L. Croitor, E. B. Coropceanu, G. Duca, A. V. Siminel, M. S. Fonari, Polyhedron 2017 129, 9-21 d) C. Ordonez, M. Fonari, J. Lindline, Q. Wei, T. Timofeeva, Cryst. Growth Des. 2014, 14, 5452-5465.

[9] a) A. Barbieri, G. Accorsi, N. Armaroli, Chem. Commun. 2008, 21852193; b) R. C. Evans, P. Douglas, C. J. Winscom, Coord. Chem. Rev. 2006, 250, 2093-2126.

[10] D. M. Schubert, D. T. Natan, D. C. Wilson, K. I. Hardcastle, Cryst. Growth Des. 2011, 11, 843-850.

[11] C. R. Groom, I. J. Bruno, M. P. Lightfoot, S. C. Ward, Acta Cryst. 2016, B72, 171-179. CSD version 5.39 updates May 2018

[12] a) A.Tarushi, X. Totta, C. P. Raptopoulou, V. Psycharis, G. Psomas, D. P. Kessissoglou, Dalton Trans. 2012, 41, 7082-7091; b) C. -F. Wang, Z -Y. Zhu, Z. -X. Zhang, Z. -X. Chen, X. -G. Zhou, CrystEngComm 2007, 9, 35-38; c) R. Smolkova, V. Zelenak, L. Smolko, D. Sabolova, J. Kuchar, R. Gyepes, J. Inorg. Biochem. 2017, 177, 143-158; d) R.

For internal use, please do not delete. Submitted_Manuscript 
Smolkova, V. Zelenak, R. Gyepes, D. Sabolova, N. Imrichova, D. Hudecova, L. Smolko, Polyhedron 2018,141, 230-238.

[13] a) G. M. Sheldrick, Acta Crystallogr. 2015, C71, 3-8; b) G. M. Sheldrick, Acta Crystallogr. 2008, A64, 112-122.

[14] C. F. Macrae, P. R. Edgington, P. McCabe, E. Pidcock, G. P. Shields R. Taylor, M.Towler, J. van de Streek, J. Appl. Crystallogr. 2006, 39 453-457.

[15] Gaussian 16, Revision A.03, M. J. Frisch, G. W. Trucks, H. B. Schlegel, G. E. Scuseria, M. A. Robb, J. R. Cheeseman, G. Scalmani, V. Barone, G. A. Petersson, H. Nakatsuji, X. Li, M. Caricato, A. V. Marenich, J. Bloino, B. G. Janesko, R. Gomperts, B. Mennucci, H. P. Hratchian, J. V. Ortiz, A. F. Izmaylov, J. L. Sonnenberg, D. Williams-Young, F. Ding F. Lipparini, F. Egidi, J. Goings, B. Peng, A. Petrone, T. Henderson, D. Ranasinghe, V. G. Zakrzewski, J. Gao, N. Rega, G. Zheng, W. Liang M. Hada, M. Ehara, K. Toyota, R. Fukuda, J. Hasegawa, M. Ishida, T. Nakajima, Y. Honda, O. Kitao, H. Nakai, T. Vreven, K. Throssell, J. A Montgomery, Jr., J. E. Peralta, F. Ogliaro, M. J. Bearpark, J. J. Heyd, E. N. Brothers, K. N. Kudin, V. N. Staroverov, T. A. Keith, R. Kobayashi, J. Normand, K. Raghavachari, A. P. Rendell, J. C. Burant, S. S. lyengar, J. Tomasi, M. Cossi, J. M. Millam, M. Klene, C. Adamo, R. Cammi, J. W. Ochterski, R. L. Martin, K. Morokuma, O. Farkas, J. B. Foresman, D. J. Fox, Gaussian, Inc., Wallingford CT, 2016.

[16] J.-D. Chai, M. Head-Gordon, J. Chem. Phys. 2008, 128, 084106(1-15).

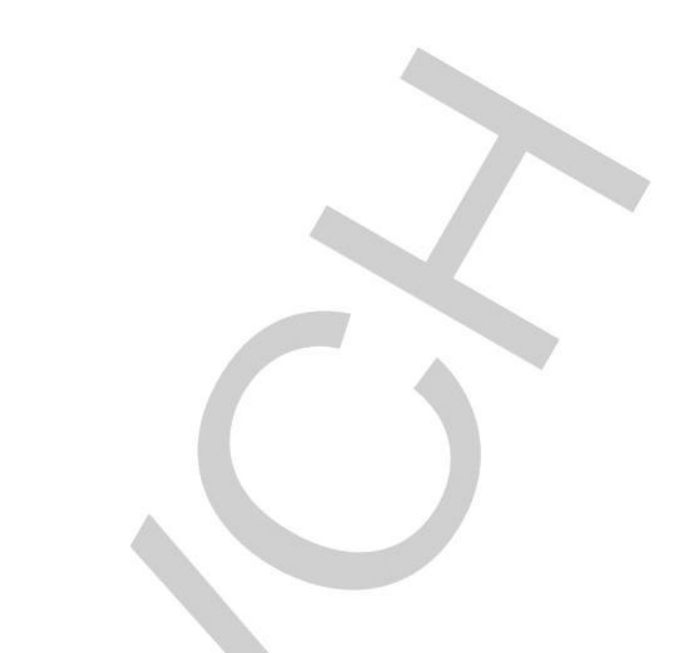




\section{Entry for the Table of Contents}

\section{FULL PAPER}

The solid state emission properties of three discrete $\mathrm{Zn}$ and $\mathrm{Cd}$ coordination compounds accommodating cyclic triimidazole as guest are investigated. The intriguing photophysics of the organic phosphors is preserved and differently affected by the metal thanks to the presence of $\mathrm{H}$ aggregates in the crystal structures.

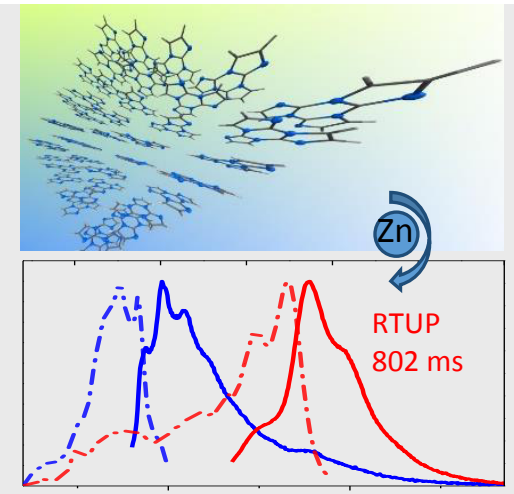

Elena Cariati, * Alessandra Forni, * Elena Lucenti, Daniele Marinotto, Andrea Previtali, Stefania Righetto, Chiara Botta, Victor Bold, Victor Ch. Kravtsov, Marina S. Fonari*

Page No. - Page No.

Extrinsic heavy metal atom effect on the solid state room temperature phosphorescence of cyclic triimidazole 
Click here to access/download
Supporting Information
SI.docx Click here to access/download
Supporting Information
SI.docx

Click here to access/download
Supporting Information
SI.docx 
Click here to access/download Supporting Information Comp2_checkcif.pdf 
Click here to access/download Supporting Information Comp3_checkcif.pdf 
Click here to access/download Supporting Information Comp1_checkcif.pdf 
Click here to access/download Supporting Information Comp4checkcif.pdf 